\title{
Estratégias Alimentares de Mães de Crianças Desnutridas e Eutróficas: estudo qualitativo mediante observação gravada em vídeo
}

\author{
Feeding strategies of mothers of malnourished and eutrophic \\ children: a qualitative study through videotaped observations
}

Gimol Benzaquen Perosa ${ }^{1}$

Maria Antonieta de Barros Leite Carvalhaes ${ }^{1}$

Maria Helena D’Aquino Benício ${ }^{2}$

Flávia Cristina Pereira Silveira ${ }^{1}$

${ }^{1}$ Faculdade de Medicina de Botucatu, UNESP. Avenida Bento Lopes 679, Jardim Santo Inácio (Rubião Junior). 18618-970 Botucatu SP.

gimol@fmb.unesp.br

${ }^{2}$ Departamento de Nutrição da Faculdade de Saúde Pública da Universidade de São Paulo

\begin{abstract}
The scope of this study was to identify and compare maternal feeding strategies and characteristics of the interaction between mothers of malnourished and eutrophic children. Eight pairs of mother/malnourished child and eight pairs of mother/eutrophic child (aged between 9 to 24 months) living in poor inner areas, were videotaped during meals, at home. Through analysis of the videos, the strategies were identified and episodes qualitatively analyzed, according to the peculiar characteristics of the interaction, especially maternal responsivity. There were no significant differences in strategies used by the mothers of both groups. The observations of the episodes have shown that feeding a child is a highly interactive process, dependent upon the abilities and characteristics of both partners. The success of feeding appears to be associated with contextual conditions, maternal responsivity and also to the appetite and flexibility of the child. It is suggested that, in projects geared to malnourished children, besides supplements and feeding orientation, special attention be given to maternal self esteem and in helping mothers to deal with children suffering from loss of appetite.
\end{abstract}

Key words Child malnutrition, Mother-child interaction, Maternal responsivity
Resumo Neste estudo procurou-se identificar e comparar as estratégias maternas para a alimentação de filhos e as características da interação das mães com crianças desnutridas e eutróficas. Oito pares de mães/crianças desnutridas e oito pares de mães/crianças eutróficas (com idades entre 9 e 24 meses), moradores de áreas pobres, foram observados e filmados durante uma refeição nos domicílios. A partir dos vídeos, as estratégias foram identificadas e os episódios analisados qualitativamente, buscando-se apreender as características peculiares da interação, especialmente a responsividade materna. Não se observaram grandes diferenças nas estratégias utilizadas pelas mães dos dois grupos. As observações de episódios mostraram que alimentar uma criança é um processo altamente interativo, que depende das habilidades e das características de ambos parceiros. $O$ sucesso alimentar pareceu associado a condições contextuais, à responsividade materna, mas, também ao apetite e à flexibilidade da criança. Sugere-se que, nos projetos direcionados a crianças desnutridas, ao lado de suplementos e orientações alimentares se dê atenção especial à autoestima materna e que se capacite as mães a lidar com a criança inapetente.

Palavras-chave Desnutrição infantil, Interação mãe-filho, Responsividade materna 


\section{Introdução}

Os modelos difundidos na década de 80 para explicar a desnutrição infantil apresentavam o estado nutricional como produto da disponibilidade de alimentos para consumo e da capacidade biológica de utilização dos nutrientes disponíveis, condicionada ao estado de saúde da criança ${ }^{1}$.

No início da década de 90, o Comitê de Nutrição das Nações Unidas ${ }^{2}$ reconhecia os fatores psicossociais como terceira vertente de variáveis associada à desnutrição infantil, podendo potencializar os efeitos prejudiciais das variáveis macroambientais de risco (pobreza, más condições de habitação e saneamento, repetidas infecções e doenças parasitárias) e atuar como fatores protetores do desenvolvimento e crescimento infan$\mathrm{til}^{3}$. Dentre essas variáveis o maior destaque coube à qualidade do cuidado materno.

A capacidade materna de cuidar adequadamente da criança e de otimizar os recursos alimentares disponíveis atuaria como um amortecedor do impacto de um ambiente desfavorável, em especial durante os períodos de maior vulnerabilidade: a vigência de uma doença infecciosa , o desmame ou no caso de uma crise financeira ${ }^{2}$.

Estudos desenvolvidos em vários países identificaram três estilos de cuidados utilizados pelas mães: o estilo controlador, o laissez-faire e o responsivo ${ }^{4}$. No estilo altamente controlador, o cuidador tem a intenção de controlar quando e quanto a criança come, forçando-a, inclusive, a ingerir os alimentos. $\mathrm{O}$ estilo laissez-faire, oposto do anterior, parte da crença de que, desde muito pequena, a criança sabe quanto e quando comer. $\mathrm{O}$ cuidador oferece poucas ajudas e raros encorajamentos. O estilo responsivo, por sua vez, parte do princípio que a criança necessita de ajudas físicas e de incentivos durante a refeição, assim como de persistência e estratégias alimentares lúdicas e positivas por parte do cuidador. A UNICEF sugere que esse estilo seja incentivado nos programas alimentares para desnutridos e na atenção básica à saúde em áreas pobres, com alto risco de desnutrição ${ }^{5}$.

Apesar de reconhecer a importância da interação mãe/filho no cuidado alimentar, ainda há poucas evidências empíricas sobre seu papel, muitas lacunas dos mecanismos pelos quais exerce sua influência e inúmeras dificuldades metodológicas para estudá-la ${ }^{6}$.

Diversas técnicas, como entrevistas e questionários, foram utilizados pelos pesquisadores para compreender as crenças que suportam as diferentes formas de interação alimentar. Ben- tley et al. ${ }^{7}$ relataram uma série de pesquisas etnográficas, levadas a cabo na Nigéria, para investigar a percepção materna a respeito da idade ideal para introduzir a alimentação sólida, como avaliavam a alimentação com as mãos, o papel materno no ato alimentar, etc. Engle et al.,em Gana ${ }^{8}$, procuraram identificar o significado que as mães atribuíam ao estado nutricional de seus filhos e como avaliavam sua intervenção nos cuidados alimentares. No Brasil, Solymos ${ }^{3}$, utilizando metodologia qualitativa e referencial fenomenológico, entrevistou mães de crianças desnutridas, moradoras de uma favela, com o intuito de compreender a experiência vivida por essas mães.

Os estudos epidemiológicos, em sua maioria, recorreram à observação direta da interação durante a alimentação. O observador registrava, através de códigos, a presença ou ausência de comportamentos escolhidos previamente ${ }^{4,5,7}$. Essas escalas possibilitaram a observação de um grande número de díades, bom nível de concordância entre os observadores, mas, segundo os próprios autores, apresentaram limitações no estabelecimento das sequências comportamentais entre os parceiros e possíveis relações causais ${ }^{4,7}$.

Uma proposta para contornar essa limitação consiste no registro integral dos episódios alimentares, mediante gravação em vídeo, para posterior analise dos "episódios de interação". A partir deles se pode captar o sentido dos comportamentos, perceber a organização global das ações sucessivas, a "estória" que se desenrola entre os diferentes parceiros.

Para alguns autores, as interações saudáveis devem contemplar algumas qualidades essenciais: investimento, quantidade adequada de estimulação, reciprocidade e flexibilidade ${ }^{10,11}$. Outros destacam a responsividade materna como característica fundamental da interação, definida como o grau de ajuste dos elementos envolvidos no contexto aos estados comportamentais da criança. Envolve o modo como o adulto altera seu comportamento, assim como aspectos do ambiente físico circundante, às demandas e limitações da criança ${ }^{12,13}$. Especificamente com relação à situação alimentar, Satter ${ }^{14}$ propõe que para alcançar sucesso é preciso uma mãe com sensibilidade para reconhecer e valorizar as informações vindas da criança sobre quando, quanto, e em que ritmo deseja ser alimentada, e uma criança capaz de sinalizar o que deseja, com um mínimo de clareza e regularidade. Na interação alimentar positiva mãe e bebê entram em sincronia, desenvolvendo uma comunicação altamente eficiente. Eventuais episódios anoréticos, geralmente provocados por 
infecção, são contornados de modo adequado e não impõem baixo consumo de alimentos por período prolongado, além de não abalarem a interação alimentar e o apetite basal.

Apesar de preconizar que a interação mãe/ criança é um processo bi-direcional, a maioria dos estudos deu prioridade ao papel do cuidador e pouca importância à participação da criança, partindo do pressuposto que crianças pequenas, com dificuldades físicas e motoras para se auto alimentar e pouca habilidade comunicativa para sinalizar os tipos de ajuda de que necessitam, inevitavelmente, precisam dos pais para compensar sua imaturidade inicial ${ }^{4,13}$.

A escassa literatura brasileira e internacional sobre interação mãe/filho durante a alimentação ao lado do reconhecimento de seu papel na determinação do consumo alimentar e do estado nutricional infantil justificam estudos sobre esse tema. No presente estudo, buscou-se descrever e comparar as características da interação mãe/filho e as estratégias alimentares de mães de crianças desnutridas e eutróficas vivendo em situação de pobreza, a partir de uma análise qualitativa de episódios alimentares gravados em vídeo.

\section{Métodos}

Trata-se de um estudo observacional, descritivo, com análise qualitativa, visando a descrição das estratégias utilizadas pelas mães e compreensão das características das interações mãe/filho durante uma refeição. A pesquisa recebeu parecer favorável do Comitê de Ética em Pesquisa. As mães foram convidadas a participar do estudo e assinaram Termo de Consentimento Livre e Esclarecido.

Estudou-se uma amostra intencional, selecionada em serviços públicos de atenção básica à saúde, em áreas periféricas de cidade de porte médio do interior paulista. Foram estudadas 8 duplas mãe/filho desnutrido e 8 duplas mãe/filho eutrófico, tamanho que pareceu suficiente para atingir os objetivos propostos. Todas as crianças tinham entre 12 e 24 meses, idade de grande vulnerabilidade da interação mãe/filho durante a alimentação, dada a transição de uma situação de total dependência do cuidador para o início da alimentação autônoma, além da ocorrência de modificações na consistência e diversidade de alimentos oferecidos. As infecções recorrentes nesse período exercem, também, um impacto negativo sobre o apetite, aumentando o risco de dificuldades na interação ${ }^{7}$.
Para seleção das duplas foram adotados os seguintes critérios de inclusão: a) idade da criança entre 12 e 24 meses; b) ausência de patologias crônicas com impacto negativo sobre o apetite e crescimento infantil; c) criança cuidada e alimentada habitualmente pela mãe, biológica ou social. Para seleção de crianças desnutridas, índice altura/idade menor do que o percentil 3 do padrão NCHS/OMS, caracterizando processos de desnutrição de longa duração (WORLD HEALTH ORGANIZATION) ${ }^{15}$. Para seleção de crianças eutróficas, a) índice altura/idade acima do percentil 25 do mesmo padrão e b) residir próximo e ser atendida na mesma unidade de saúde onde as crianças desnutridas foram identificadas. Foram excluídas crianças com índice peso/ altura igual ou acima do percentil 85, potencialmente com sobrepeso ou obesidade, e crianças nascidas com menos de $2500 \mathrm{~g}$.

$\mathrm{Na}$ primeira visita ao domicílio, realizou-se uma entrevista com as mães sobre características socioeconômicas e de saúde física e mental das díades, para selecionar a amostra, iniciar a aproximação e reduzir os efeitos de possível reatividade nas situações de observação e filmagem subsequentes. Em uma segunda visita, duas entrevistadoras computaram, a partir de um formulário previamente estruturado, os comportamentos maternos e da criança durante o almoço. Esta abordagem aumentou a familiaridade entre as observadoras e as díades, além de permitir a testagem de uma escala construída para este tipo de estudos. Em uma terceira visita, agendada de comum acordo com as mães, foi realizada a filmagem durante a refeição. As análises apresentadas foram produzidas com base nos vídeos referentes a este último contato. Durante toda a gravação a câmera focalizava a díade. Nos raros momentos em que um dos participantes se retirava do local se dava prioridade à filmagem de quem permanecia no local da refeição.

Optou-se por utilizar o episódio como recorte de análise dos fluxos interacionais complexos. Cada episódio se iniciava com o comportamento materno de apresentar comida à criança, se registravam as sequências interativas, até o momento em que o prato era retirado da frente da criança. Os vídeos foram vistos exaustivamente por um dos pesquisadores, sem saber se a criança era desnutrida ou eutrófica, a fim de identificar, em um primeiro momento, as diferentes estratégias utilizadas pela mãe. A seguir, registrava-se se a criança, no fim da refeição, havia ingerido todos os alimentos colocados no prato, ou deixado sobra insignificante frente ao que havia 
sido oferecido ${ }^{4,16}$. Finalmente, procurou-se identificar, nos episódios, as características interativas: investimento no contato, reciprocidade e flexibilidade ${ }^{10,11}$, dando atenção especial à responsividade materna ${ }^{12}$. Um segundo observador, também participante da pesquisa, analisou de forma independente os episódios, utilizando os mesmos referenciais teóricos do primeiro pesquisador. Todas as divergências de interpretações foram discutidas para obtenção de acordo quanto às categorias de análise. Somente após completar a identificação das estratégias maternas e a análise das interações de cada díade, identificava-se a que grupo a criança pertencia (desnutrido ou eutrófico), com vistas a captar e interpretar as possíveis características interativas peculiares a cada um dos grupos.

\section{Resultados}

Os episódios tiveram duração de 20 a 40 minutos. Seis crianças eutróficas completaram a refeição, em oposição a quatro desnutridas.

Identificaram-se cinco estratégias maternas: a) distrair; b) facilitar; c) insistir e encorajar; d) barganhar e ceder; e) dar total autonomia. Não se observaram diferenças marcantes na quantidade e nas estratégias que as mães dos dois grupos utilizaram para alimentar a criança. $O$ fato de a criança consumir tudo ou quase tudo que foi servido, também, não pareceu associado a uma estratégia específica, mas sim à singularidade e qualidade das diferentes interações que, por sua vez, estavam condicionadas ao contexto e a variáveis comportamentais relativas à mãe e à criança.

a) Distrair

A estratégia, denominada popularmente de "olha o aviãozinho", isto é, acreditar que distraindo a criança inapetente ela acaba comendo sem perceber, foi bastante presente nas mães dos dois grupos. Em quase todos os episódios, a TV era ligada quando a criança era instalada na frente do prato e, sintonizada, preferencialmente, em programas de desenhos animados. Se a TV não estava ligada, as mães tentavam chamar a atenção para algum estímulo interessante do ambiente ou para coisas inventadas ou imaginárias "olha o passarinho que vai entrar pela janela", enquanto aproveitavam para enfiar o alimento na boca. Se, no primeiro momento, essa tática surtia efeito, as "novas surpresas" não facilitaram o consumo alimentar. b) Facilitar a atividade

Dando força a pesquisas que associam sucesso alimentar a um estilo responsivo ${ }^{4}$, algumas mães, como no Episódio 1, delimitavam o contexto, se adaptavam às características da criança, consideravam as limitações psicomotoras impostas pela idade e facilitavam o acesso ao alimento. Permitiam comportamentos autônomos, mas eram, também, ativas nas ajudas, incluindo ajudas físicas.

Episódio 1 - A mãe de K. prepara o prato e coloca na frente da filha, sentada no cadeirote. Posiciona-se a sua frente e prepara uma colher. A criança leva a colher até a boca. Esse comportamento, sem muita conversa se repete algumas vezes. K. segura a ponta da colher e a comida cai antes de chegar na boca. A mãe monta uma nova colherada e leva à boca da criança, com a "ajuda" de K. K. pega um pedaço de carne com a mão e leva à boca. A mãe espera que engula e, em seguida, lhe dá várias colheradas. K. diz que não quer mais. “Tá cheia?”, a criança assente com a cabeça. "Mais um pouco?” A mãe prepara uma colher com quantidade menor, repousa no prato e espera que K. pegue. Prepara mais algumas colheradas, sempre pondo um pouco de carne. "Tem carne que você gosta”. K. diz que acabou. Ela tenta dar mais uma colher. K. vira a cabeça. Ela tira o prato e traz uma caneca de água. (K., 21 meses, eutrófica).

Nesta díade pode-se observar uma mãe altamente responsiva aos sinais emitidos pela criança. Houve flexibilidade em aceitar as iniciativas de independência e respeito ao ritmo, mas ela não deixou de insistir, encorajar, contemplar cada colherada com o alimento preferido pela criança e oferecer ajudas físicas. Esse dado fortalece as evidências obtidas por Guldan et al. ${ }^{16}$ onde crianças pequenas da área rural de Bangladesh consumiram mais alimentos frente a uma pressão leve com ajuda física, enquanto que, com crianças mais velhas, as verbalizações encorajadoras foram mais eficientes.

Deve-se considerar, também, que neste episódio o interesse da criança pelo alimento e sua flexibilidade frente às propostas maternas contribuíram para o sucesso alimentar, confirmando que a interação não depende apenas dos comportamentos maternos, mas do conjunto de comportamentos da díade.

No episódio descrito a seguir (Episódio 2), as tentativas maternas de facilitar a alimentação de uma criança pequena, também foram efetivas. A mãe dava comida na boca, respeitava seu 
ritmo e delimitava bem o contexto, sentando-se à mesa e segurando firmemente a criança no colo.

Episódio 2 - A mãe de S. prepara o prato, coloca na mesa e senta com ela no colo. Apesar da criança estar de costas para a mãe, em frente ao prato, ela observa de lado quando a criança engole e oferece nova colherada. S. abre a boca e a mãe aproxima a colher. Ela espera a criança engolir. Prepara nova colherada. A criança curva-se em direção à colher. A mãe aproxima a colher e ela abre a boca... Esporadicamente, a mãe faz comentários sobre o alimento. S. comeu quase tudo que a mãe colocou no prato. (S., 14 meses, desnutrida).

Entretanto, estratégias semelhantes ás da mãe de $S$. fracassaram em outra díade, como se verá no episódio subsequente (Episódio 3).

c) Insistir e encorajar

Apesar da mãe de A tentar facilitar a alimentação, o episódio a seguir mostra uma situação alimentar bastante tensa e uma criança que não comeu quase nada. A. era uma criança mais velha, inflexível na sua recusa à alimentação sólida. Com crianças mais velhas, mais autônomas, a forma da mãe facilitar o comportamento alimentar parece mais associada a oferecer utensílios adequados às habilidades da criança, ou mesmo em apresentar os alimentos picados, misturados, sem muito caldo, para que ela possa comer com pouca ajuda ou com a mão, acompanhados de instruções, incentivos e encorajamentos verbais ${ }^{16}$.

Episódio 3 - A. está sentada na cama, com um pote de comida na sua frente e a mãe sentada ao lado. Apesar de bem próxima da criança, parece preocupada com os filhos que disputam, na outra sala, uma pipa. Fala com eles, enquanto A. fica batendo a colher no prato. A mãe, sem olhar, vai repetindo "come A., come". Depois de 3 colheradas parcialmente derrubadas, ela não quer mais comer. A mãe diz, "deixa que eu dou”. Ela recusa. A mãe coloca a criança no colo, mas A. pega novamente a colher e não aceita ser alimentada. A mãe repete várias vezes: “só um pouquinho, come A”. A criança quer sair do colo, a mãe segura firme e dá um brinquedo para ela. Fala: "come que a mãe vai levar ver o nenê", "daqui a pouco o pai está aqui”. A criança diz "não” e a mãe responde: "não tem querer" e tenta por a comida á força na boca da filha. A criança se esquiva. A mãe tenta fazer aviãozinho com a colher, ela joga a cabeça para trás. A mãe tenta novamente por a colher dentro da boca. A criança chora e a mãe pára. A. puxa a blusa da mãe (quer o peito?). A mãe tenta novamente dar a colher, ela chuta a colher.
“Come A". Após varias tentativas maternas de oferecer a colher, A. chutar e puxar a blusa da mãe,ela cede e oferece o peito (A. 17 meses, desnutrida).

A. iniciou a refeição na cama, contexto altamente inadequado para alimentação, com colher (de sopa) e recipiente impróprios (pote com pequeno diâmetro), considerando suas habilidades psicomotoras. O contexto também foi menos favorável do que os descritos nos episódios 1 e 2, pois esta mãe tinha que compartilhar a atenção e os cuidados com outros filhos.

Encorajamentos para a criança comer, na forma de expressões ("mais um pouco"), repetidas inúmeras vezes, quase mecanicamente, foram utilizadas por esta mãe e varias outras. Poucas vezes foram atendidas pelas crianças, possivelmente porque as mães recorriam a essa estratégia quando as crianças já demonstravam que não queriam mais comer.

No episódio acima, frente às recusas, a mãe tentou distraí-la com brinquedos, pediu insistentemente que comesse e, inclusive, tentou alimentá-la de forma coercitiva, enfiando a colher à força na boca. Como a criança reagiu chorando, a mãe parou prontamente. Há relatos de que práticas coercitivas levam a criança a se desinteressar pelos alimentos, tendo como consequência prejuízos à saúde, ao crescimento e a saúde mental da criança ${ }^{4}$. Entretanto, no episódio de A., a relação observada pareceu inversa, a mãe usou de técnica coercitiva após e em resposta às recusas da criança e a ineficácia desta estratégia foi clara. A. mostrou, também, pouca flexibilidade frente às tentativas maternas de alimentála. No embate final, a mãe acabou amamentando a filha, como a criança queria.

\section{d) Barganhar e ceder}

O comportamento de ceder aos desejos das crianças foi bastante frequente. Quando o conflito se instalava, a mãe optava por ceder em alguns momentos, por não transigir em outros, criando um contexto de regras inconsistentes, propício à birra. Crianças dessa faixa etária que já possuem firmeza na locomoção (que possibilita intensa movimentação e exploração do ambiente) brigam por autonomia. A maioria das mães, nos episódios observados, pareceu disposta a contemplar os desejos e idiossincrasias das crianças.

Episódio 4- A mãe de I. prepara o prato, coloca a criança sentada no colo. Ele aceita as primeiras colheradas, a mãe vai oferecendo novas colheradas e ele come... I.tenta ir para o chão. A mãe ajuda, ele sobe no velotrol, vai até a porta e 
volta para perto da mãe. Ela lhe dá outra colherada. Vai e volta várias vezes. A mãe dá risada. I. volta para perto dela que oferece a colherada, mas I. sai andando com o velotrol para perto da porta. A se desloca para a frente da porta e ele come mais uma colherada. Ele pede para que tire a cadeira para que ele possa passar com o velotrol. A mãe ,levanta, dá uma colherada para ele e tira a cadeira do caminho... Ele diz que não quer mais, a mãe "não quer mais mesmo?". Ele sai com o velotrol, ela leva o prato até a cozinha... (I 19 meses, eutrófico).

A mãe de I. aceitou qualquer comportamento contanto que a criança comesse. Ela sempre cedeu, mas pareceu aceitar bem a situação e divertir-se com as idas e vindas do filho, em um contexto em que podia dar atenção total a ele. Entretanto, se neste episódio, se está à frente de uma mãe com alta flexibilidade, adaptando-se à criança com prazer, em outras situações, como nos casos de A (episódio 3) e L (Episódio 5), o comportamento de ceder esteve associado a mães permissivas, aparentando falta de confiança na sua capacidade de colocar limites e controlar a criança. As duas crianças (A. e L.) comeram muito pouco.

e) Dar total autonomia

Confirmando achados de outras pesquisas, com populações latino-americanas ${ }^{4,7}$, algumas mães utilizaram estratégias pouco ativas, isto é, posicionavam a criança na frente do prato e se afastavam, com poucas interferências. Esse estilo alimentar aconteceu, principalmente, no inicio das refeições, com díades mãe/criança desnutrida. De início, esse procedimento pareceu bem sucedido, principalmente, se a criança estava interessada em comer. Elas escolhiam os alimentos de sua preferência, em geral a carne, aumentando as chances de ingerir a melhor fonte de proteína do prato. Mas, no caso das crianças desnutridas, com mais sinais de inapetência e falta de destreza para se alimentar sozinhas, a baixa interferência materna resultou em interrupção da alimentação, mesmo quando, de início, havia algum interesse em comer. As crianças derrubavam a comida que pretendiam levar à boca, brincavam com o alimento, se distraiam e abandonavam a refeição. A partir desse momento, as mães mudavam de estilo, tentando fazer a criança a voltar a comer, mas esse retorno era muito difícil, como pode ser observado no episódio abaixo.

Episódio 5- L. está sentada no sofá, ao lado do irmão, cada um com uma vasilha de plástico, com comida. A mãe está sentada na frente dos filhos, ora fechando os olhos (cansada? Desanimada?) ora observando os dois. L. pega um pedaço de carne do prato do irmão, mastiga e cospe na sua vasilha. A mãe retira o pedaço mastigado, sem dizer nada. L. pega algumas colheradas e leva à boca. Estica-se no sofá e põe o pé dentro do prato. A mãe não se manifesta. L pega outro pedaço de carne. Fica de pé, no sofá, mastiga e cospe. Levanta a colher de sopa com alguns grãos de arroz, que derruba no sofá. Pega alguns grãos do sofá e leva à boca. Diz que não quer mais. A mãe insiste: "Mais um pouco". A criança vira o rosto. A mãe retira o prato e L. vai atrás pedindo água. (L. 21 meses, desnutrida).

Segundo Satter ${ }^{13}$, os pais, muitas vezes, consideram que comer é um ato instintivo, sem perceber que é um comportamento complexo, com habilidades que tem que ser aprendidas gradualmente. O fato de uma criança já ter condições de segurar a colher e, eventualmente, conseguir levála à boca, não significa que ela está apta para se alimentar sozinha. Na observação acima, L. é uma criança inapetente, com poucas habilidades para comer sozinha, posicionada de forma inadequada, tendo a frente uma mãe pouco responsiva. Criou-se, então, uma interação caracterizada pela falta de reciprocidade: comportamentos emitidos sem resposta imediata ou mesmo mediata do parceiro. A criança comeu muito pouco.

Algumas mães que deixavam a criança comer sozinha estavam envolvidas em outras tarefas domésticas, acabar o almoço ou cuidar de outros filhos. Mas, nem sempre outras atividades competiram com a atenção direta à criança. Certas mães estavam presentes, observavam, mas não interferiam. Sua limitada participação/envolvimento no episódio parecia mais determinada pelo seu estado físico e emocional: cansaço, fastio, baixa autoconfiança. Entretanto, nem sempre a estratégia de dar autonomia resultou em fracasso alimentar. No caso de outras crianças, com mais apetite, mais persistentes e com maior destreza, apesar da vigilância materna à distância, elas completaram a refeição.

\section{Discussão}

Contrariando as expectativas, não foram observadas grandes diferenças nas estratégias alimentares a que recorriam mães de crianças desnutridas e eutróficas. As estratégias eram semelhantes, apesar das dificuldades encontradas para alimentar uma criança inapetente serem bem maiores. Estas, em sua maioria desnutridas, foram 
bastante resistentes às tentativas maternas para alimentá-las.

O conjunto de observações mostrou que além do comportamento da mãe, outros fatores pareceram influenciar no sucesso das estratégias alimentares: as condições situacionais, a quantidade, a palatabilidade e a aparência dos alimentos, o respeito à fase de desenvolvimento neuropsicomotor e o apetite da criança.

Para Chatoor e $\operatorname{Egan}^{17}$ ao lado da anorexia que acompanha quadros de desnutrição infantil crônica ou infecções, pode-se encontrar a anorexia da separação, "não-orgânica", associada a uma dinâmica imprópria no momento da alimentação. Ocorre, geralmente, com crianças com mais de 8 meses que querem prolongar a amamentação exclusiva, persistem em dar preferência a alimentos líquidos ou batidos, parecem desinteressadas pelos alimentos em geral e apresentam quadros de birra.

Neste estágio de desenvolvimento, as crianças estão vivenciando a separação materna e sua própria individuação. Apesar de apresentarem, ainda, forte dependência do adulto e habilidades limitadas de preensão, iniciam uma luta pela autonomia e controle de algumas funções diárias que, associada à firmeza na locomoção e interesse pela exploração do ambiente, tornam a situação alimentar bastante conflituosa. Nesta pesquisa, o desinteresse pelo alimento e recusas alimentares foram comuns, assim como tentar comer sozinho, brincar com a comida e afastar-se do local da refeição. Por outro lado, pareceu que a delimitação do espaço alimentar, com cadeirotes ou mesmo com mesas e cadeiras, influiu positivamente, proporcionando estabilidade ao prato e contenção do comportamento exploratório da criança. Oferecer vasilhames (maiores) e colheres (menores), apropriadas ao tamanho e estágio de desenvolvimento psicomotor, também pareceu facilitar a autoalimentação, uma aspiração das crianças desta faixa etária.

Várias crianças encerraram a refeição sem ingerir todo o alimento oferecido. É possível que as mães, sabendo que estavam sendo observadas, encheram mais o prato de comida, numa demonstração de bons cuidados. Entretanto, segundo a literatura, crianças desta faixa etária, rotineiramente, não completam a refeição ${ }^{4,7}$. As crianças observadas, especialmente as desnutridas, eram inflexíveis aos apelos maternos, abandonavam o local da alimentação e mostravam desejos conflitantes aos das mães (queriam doces, suco, ou mesmo ser amamentadas ao peito).

Estima-se que, nesta idade, de 25 a $35 \%$ das interações alimentares são problemáticas ${ }^{17}$. Segun- do Engle e Zeitlin ${ }^{4}$, 65\% das crianças nicaraguenses, pobres, por eles observadas, não terminaram a refeição. Além de ser um período de transição da alimentação pastosa para sólida, é uma fase de desenvolvimento em que as crianças são bastante suscetíveis a infecções, especialmente em ambientes insalubres e de pobreza. Dependendo de como a mãe lida com eventuais episódios de recusa alimentar, as crianças podem continuar tendo episódios esporádicos de pouco apetite ou persistir neste padrão, tornando muito difícil a interação mãe/filho durante as refeições ${ }^{14}$.

Possivelmente, se a mãe reduzisse o tamanho da porção servida e, se necessário, servisse uma porção adicional, ela evitaria sua frustração pessoal. Nesta pesquisa observou-se que refeições muito demoradas resultavam em perda da atratividade do alimento, que esfriava, ficava espesso e pouco atraente. Aumentar a probabilidade de experiências alimentares bem sucedidas seria uma forma de diminuir o desamparo materno e aumentar sua motivação e seu investimento na criança ${ }^{18}$.

Algumas mães pareciam mais passivas e pouco responsivas, especialmente no início da refeição e só demonstravam maior envolvimento, propondo distrações, barganhas e encorajamentos verbais, quando as crianças começavam as recusas. A presença física da mãe, sua disponibilidade em oferecer ajudas, manter o ritmo da refeição, reduzir distrações, especialmente com crianças menores, pareceu aumentar as chances de um episódio alimentar bem sucedido. Um estudo, desenvolvido no México, com crianças entre 8 e 22 meses, mostrou forte associação entre a frequência de ajudas físicas oferecidas pela mãe com a quantidade de alimentos consumidos pela criança e seu estado antropométrico ${ }^{4}$.

Pode ser que a passividade observada desde o início da refeição, assim como os encorajamentos repetitivos e desmotivados diante da recusa alimentar, reflitam uma baixa autoestima materna, fruto de fracassos anteriores em suas tentativas de alimentar os filhos ou de controlar outras adversidades do contexto familiar. Solymos ${ }^{3}$, entrevistando mães de desnutridos na cidade de São Paulo, constatou que a experiência de impotência frente a dificuldades recorrentes na vida contribuía para uma baixa autoestima, bem como para uma visão cada vez mais fatalista e sem esperança. Segundo Seligman ${ }^{18}$, repetidas experiências de incontrolabilidade, isto é, respostas do indivíduo que não conseguem modificar o ambiente, geram um quadro de desamparo adquirido, com sintomas semelhantes ao de quadros depressivos. Segundo este referencial teórico, pode-se levantar a 
hipótese de que as estratégias pouco criativas das mães, de comprovada baixa eficácia, e a falta de ajudas mais ativas para a criança comer, reflitam a crença de que seus comportamentos são impotentes/inoperantes para enfrentar as dificuldades alimentares. Esse quadro de desânimo pôde ser evidenciado por frases que precederam algumas das refeições observadas: "hoje você não vai querer comer, né?", "será que você vai comer hoje? Será esse milagre?”.

Assim como em outros estudos realizados na América Latina e Ásia, o controle aversivo ou coerção para a criança comer não foi um comportamento habitual das mães ${ }^{4,5,7}$. Ao contrário, a dificuldade em colocar limites esteve muito presente. Isto pode ter ocorrido pelo fato das mães estarem sendo filmadas, mas pode decorrer, também, de conceitos educacionais, bastante difundidos nos dias de hoje, que enfatizam a importância de não frustrar (ou traumatizar) a criança opondo-se às suas vontades. Parte-se do pressuposto que a criança sabe o que lhe convém, ou que somente o tempo poderá fazê-las modificar um comportamento indesejável. As tentativas paternas de colocar limites acabam despertando sentimentos de culpa e, consequentemente, as iniciativas e barganhas da criança não encontram resistência firme ${ }^{19}$. Quando a situação se torna crítica, como na inapetência crônica e desnutrição, as mães tentam assumir outro comportamento, mas a total inflexibilidade por parte da criança e os quadros de birra já instalados forçam as mães a ceder.

O recorte das observações em episódios alimentares, com cadeias longas de sequências interativas, permitiu contornar algumas limitações referidas em outros estudos ${ }^{4,5}$ e avançar na descrição e compreensão dos comportamentos maternos. Pode-se observar, por exemplo, que os encorajamentos, assim como outros comportamentos mais ativos de ajudar a criança a comer, sucederam as recusas alimentares, caracterizando seu caráter compensatório. Contrariando as expectativas, comportamentos coercitivos maternos, pressões e verbalizações negativas, já no início da refeição, não foram os responsáveis pelas recusas alimentares da criança, mas, foram emitidos pela mãe frente à resistência do filho em aceitar a comida, o que caracterizaria um mecanismo de causalidade reversa ${ }^{5}$. Por outro lado, crianças mais receptivas e interessadas nos alimentos (mais saudáveis e bem nutridas) encorajaram comportamentos mais responsivos de suas mães. Observando repetidamente os episódios filmados, pareceu que, provavelmente, se está di- ante de uma relação de interdependência bidirecional entre o comportamento da mãe e da criança: as crianças mais difíceis de alimentar abalavam a autoconfiança materna e essas mães, estressadas e cansadas, com várias tentativas fracassadas de alimentar satisfatoriamente a criança, investiam menos nela e no seu consumo alimentar, agravando seu estado nutricional e de saúde.

Finalmente, cabem algumas considerações sobre aspectos metodológicos e limitações do presente estudo.

Em primeiro lugar, deve-se ter em mente que as análises se limitaram a um único episódio alimentar de cada díade, devido às dificuldades de operacionalizar a observação de vários episódios. Apesar de não contar com recusas explícitas em participar da pesquisa, as dificuldades para encontrar algumas mães nos dias agendados ou a alegação de múltiplos empecilhos no horário estipulado, exigindo novos agendamentos, pareceu sugestivo de que as mães se incomodavam, de alguma forma, com o fato de serem observadas. Como consequência, contar com apenas uma observação gravada de cada díade, não permite rotular ou classificar o estilo alimentar das mães estudadas, pois a variabilidade intraindividual das estratégias maternas ainda é desconhecida.

Além disso, apesar das observações acontecerem no ambiente natural, em data e horários previamente agendados segundo conveniência materna, a presença de duas pessoas estranhas, mantendo relativa distância da interação familiar, em cômodos especialmente pequenos, pode ter interferido nas atitudes dos participantes. É possível que comportamentos socialmente censurados, como agressão física ou verbal dirigida à criança, tenham sido reprimidos. Ou elas podem ter reduzido a insistência para que a criança comesse, comprometendo sua ingestão alimentar, com o intuito de evitar o choro, que poderia ser interpretado como descuido ou mesmo maus tratos. Por outro lado, pode-se também supor que os resultados contenham algum viés positivo: as mães podem ter tentado apresentar os comportamentos que supunham serem os mais adequados, aumentando as porções, oferecendo mais ajudas físicas e incentivos que de rotina. Apenas com mais observações das díades e a consequente redução da reatividade dos observados estas hipóteses poderiam ser testadas.

Ainda, neste trabalho, a análise ateve-se ao papel de alguns aspectos contextuais e aos comportamentos da mãe e da criança. Possivelmente, variáveis de outra ordem, tanto da mãe (estado marital, ocupação, número de crianças sob 
seus cuidados, etc), quanto da criança (peso ao nascer, ordem de nascimento, sexo, etc.), também devem ter um papel no tipo de interação que se estabelecia na díade durante a alimentação da criança e poderão merecer análise futura.

\section{Considerações finais}

A observação de episódios alimentares de crianças desnutridas e eutróficas entre 12 e 24 meses de idade, em ambiente de pobreza, mostrou que se trata de processo altamente interativo, que depende das habilidades e características de ambos os parceiros.

Corroborando estudo brasileiro com população de baixa renda ${ }^{20}$, algumas mães obtiveram sucesso ao alimentar, lançaram mão de várias estratégias adequadas e foram responsivas às necessidades da criança, mostrando que, mesmo em condições econômicas e sociais precárias, elas cumpriam seu papel de proteção e cuidado com competência. No entanto, o comportamento materno só pareceu determinar parte do curso da interação. Vários fatores pareceram interferir no sucesso ou fracasso das tentativas maternas, em especial a inapetência da criança. Ela teve um papel bastante ativo em seu consumo alimentar.

Pesquisa de revisão, que analisou os principais projetos de prevenção e combate à desnutrição nas últimas décadas, demonstrou que as ações prioritárias tem sido a entrega mensal de alimentos e suplementos e, que, as poucas experiências de aconselhamento se limitaram a orientar normas higiênicas e opções alimentares ${ }^{21}$. As dificuldades de contornar a inapetência infantil já instalada e o quadro de desamparo materno, observados neste estudo, alertam para a necessidade de: a) identificar quando se inicia e como a mãe lida inicialmente com a inapetência e b) implementar intervenções preocupadas em melhorar a qualidade das relações mãe/filho e ações educativas que permitam à mãe se habilitar para atuar frente à criança inapetente.

\section{Colaboradores}

GB Perosa, MABL Carvalhaes, MHD Benício e FCP Silveira participaram igualmente de todas as etapas da elaboração do artigo. 


\section{Referências}

1. Ruel MT, Arimond M. Measuring childcare practices: approaches, indicators, and implications for programs. Food Policy Review 2003; 6:1-81.

2. United Nations(UN)/ACC/SCN. Nutrition-relevant actions: some experiences from the eighties and lessons for the nineties. Genebra: UN/ACC/SCN; 1991.

3. Solymos GMB. A experiência vivida de mães de desnutridos: um novo enfoque para intervenção em desnutrição infantil. In: Sawaya AL, organizador. Desnutrição urbana no Brasil em um período de transição. São Paulo: Cortez; 1997. p.127-153

4. Engle PL, Zeitlin MF. Active feeding behaviour compensates for low interest in food among young Nicaraguan children. J Nutr 1996; 126(7):1808-1816.

5. Ha PB, Bentley ME, Pachon H, Sripaipan T, Caulfield LE, Marsh DR, Schroeder DG. Caregiver styles of feeding and child acceptance of food in rural Viet Nam. Food Nutr Bull 2000; 23(4):92-98.

6. Latham MC, Ramakrishman O. Cornell colloquium on care and nutrition of the young child overview. Food Nutr Bull 1995; 16:286-292.

7. Bentley ME, Stallings RY, Fukumoto M, Elder JA. Maternal feeding behavior and child acceptance of food during diarrhea convalescence and health in the Central Sierra of Peru. Am J Public Health 1991; 81(1):43-47.

8. Engle PL, Bentley ME, Pelto G. The role of care in nutrition research programs: Current research and a research agenda. Proc Nutr Soc 2000; 59(1):25-35

9. Stambak M, Barrière M, Bonica I, Maisonnet R, Musatti T, Rayna S, Verba M, organizadores. Les bébés entre eux: découvrir, jouer, inventer ensemble. Paris: PUF; 1983. p. 9-15.

10. Kreisler L. A nova criança da desordem psicossomática. São Paulo: Casa do Psicólogo; 1999.

11. Mazet P, Stoleru S. Manual de psicopatologia do recém-nascido. Porto Alegre: Artes Médicas; 1990.

12. Lordelo ER, Fonseca AL, Araújo MLVB. Responsividade do ambiente de desenvolvimento: crenças e práticas como sistema cultural de criação de filhos. Psicol Reflex Crit 2000; 13(1):73-80.
13. Piccinini CA, Alvarenga P, Frizzo GB. Responsividade como foco de interação mãe-bebê e pai-bebê. In: Piccinini CA, Seidl de Moura ML, organizadores. Observando a interação Pais-Bebês-Criança. São Paulo: Casa do Psicólogo; 2007. p. 131-154.

14. Satter E. The feeding relationship: problems and interventions. J Pediatr 1990; 117(2 Pt 2):S181-189.

15. World Health Organization Working Group Use and interpretation of anthropometric indicators of nutritional status. Bull World Health Organ 1986; 64(6): 929-941.

16. Guldan G, Zeitlin MF, Beiser AS, Super CM, Gershoff SN, Datta S. Maternal education and child feeding practices in rural Bangladesh. Soc Sci Med 1993; 36(7):925-935.

17. Chatoor I, Egan J. Nonorganic failure to thrive and dwarfism due to food refusal: a separation disorder. J Am Acad Child Psychiatry 1983; 22(3):294-301.

18. Seligman MEP. Desamparo: sobre depressão, desenvolvimento e morte. São Paulo: Hucitec; 1997.

19. Caldana RHL. A educação de filhos em camadas médias: transformação no ideário e orientação de pais. Temas Psicol. 1995; 3(1):109-122.

20. Yunes MAM, Garcia NM, Albuquerque BM. Monoparentalidade, pobreza e resiliência: entre as crenças dos profissionais e as possibilidades da convivência familiar. Psicologia: Reflexão e Critica 2007; 20(3):444-453

21. Valle NJ, Santos IS, Gigante DP. Intervenções nutricionais e crescimento infantil em crianças de até dois anos de idade: uma revisão sistemática. Cad Saude Publica 2004; 20(6):1458-1467.

Artigo apresentado em 04/06/2009

Aprovado em 05/01/2010

Versão final apresentada em 12/01/2010 